\title{
COMPARISON OF THREE NONLINEAR MODELS TO DESCRIBE THE GROWTH CURVE OF HOLSTEIN-FRIESIAN BULLS RAISED UNDER EGYPTIAN CONDITIONS
}

\author{
R.A.M. Somida \\ Animal Production Department, Faculty of Agriculture, Fayoum University, 63514 Fayoum, Egypt, \\ correspondence Email: ram04@fayoum.edu.eg
}

Received: 12/1/2021 Accepted: 18/2/2021

\section{SUMMARY}

The current study aimed to estimate the growth curve parameters through three non-linear models (Logistic, Gompertz and Richards) to determine which model best fits the data. Live weight records of 102 HolsteinFriesian bulls collected between 2017-2019 from a Holstein-Friesian herd that belongs to the Association of Livestock Development (EL- Lahhamy farm), located thirty kilometers west of Fayoum Governorate. In this work, the parameters of the studied models, asymptotic weight (A), constant of integration (b) and the maturation rate $(K)$ ranged from $626.15 \mathrm{~kg}$ to $879.82 \mathrm{~kg}, 2.708$ to 11.08 , and 0.0035 to 0.008 , respectively. According to the studied parameters of growth functions, Gompertz reached the highest numerical estimated value for (A) and the Logistic function had the lowest value. Parameter (K) estimate by the Gompertz model was similar to that obtained by the Richards model; both values were lower than those attained through the Logistic model (0.008). The inflectionpoint traits, time at Point of inflection (IPT) and weight at point of inflection (IPW) estimates ranged from $300.64 \mathrm{~kg}$ to $314.59 \mathrm{~kg}$ and 323.92 days to 336.14 days, respectively. The Richards model has the highest estimates of IPW and IPT comparedto the other models, also it had the best adjustment according to model goodness of fitcriteria, by having the lowest values for Akaike information criterion (AIC), Schwarz Bayesian information criter ion (BIC), Mean square error (MSE) and highest coefficient of determination (R2, ,14489.18, 14510.6, 317.37 and 0.9983) followed by the Gompertz, and logistic functions.

Keywords: Growth curves, Gompertz, Richards, Logistic, Holstein-Friesian bulls

\section{INTRODUCTION}

Growth, a combination of hereditary and environmental factors, is an essential physiological process in animal production which can be defined as a relationship between live weight and age or an increase in body size per time unit (Lawrence and Fowler, 2002). The aggregating importance of the Holstein breed as a source of beef beside milk requires information about growth parameters (Calo et al., 1973). Non-linear functions that relate the animal weights and ages have been primarily used in the study of the cattle growth curve (Souza et al., 2010). Fitting of nonlinear models presents a chance for summarizing the information included in the whole sequence of weight-age points into a small set of parameters which can be interpreted from a biological point of view as (A) Asymptotic weight (b) is a scaling parameter related with initial body weight and (k) is the maturing rate. These parameters are eventually used to find other growth traits. Also, by investigating the relationship between parameter $\mathrm{K}$ and the asymptotic weight $(\mathrm{A})$, the heaviest animals can be identified at younger ages (Freitas, 2005). Many studies conducted on nonlinear equations indicated that the Richards model was the best to describe the growth curve of cattle (Selvaggi et al., 2017 and Yin and König,2020). Although Richards has more computational difficulties as it is a four-parameter model, it was found to be the most suitable one due to its accuracy in predicting mature weight, which is considered an important selection goal (Selvaggi et al., 2017). The Gompertz and logistic mathematical models were found among the most frequently used functions for describing cattle growth (Duarte, 1975 and Wada et al., 1983). So, the present study aimed to compare the potential of three non-linear models (Logistic, Gompertz, and Richards) to detect which model best fits the data of Holstein bulls.

\section{MATERIALS AND METHODS}

\section{Herd management:}

Live weight records of 102 Holstein-Friesian bulls collected between the years 2017 and 2019 from a Holstein-Friesian herd cattle that belongs to The Association of Livestock Development (ELLahhamy farm), a dairy farm located about thirty kilometers west of Fayoum Governorate. Shaded open yards with a cool spraying system during the high atmospheric temperature were constructed for animal housing. Calves were weaned at the $3 \mathrm{rd}$ month of age. Three different rations were formulated and provided ad libitum to the bulls considering the average live weights obtained from the monthly weights. The three rations were as follows: (from weaning to $150 \mathrm{~kg}$ ), from 150 to $300 \mathrm{~kg}$

Issued by The Egyptian Society of Animal Production 
and from $300 \mathrm{~kg}$ to the end) which contained of $19 \%$, $16 \%$, and $14 \%$ crude protein, respectively. The total digestible nutrients (TDN\%) was 69 for all of them.

\section{Statistical analysis:}

Model parameters were analyzed using the procedure of nonlinear models (PROC NLIN) of
SAS software (SAS, 2011). Nonlinear functions used for the description of the growth curve were Gompertz, Richards, and Logistic to fit the HolsteinFriesian male growth curve. These functions are presented in Table (1).

Table 1. Non-linear functions used for modeling the growth curves and the inflection point traits formula for each as cited by (Selvaggi et al., 2017)

\begin{tabular}{ll}
\hline Models & Functions formula \\
\hline Gompertz & $\mathrm{Wt}=\mathrm{A}^{*} \exp \left(-\mathrm{b}^{*} \exp \left(-\mathrm{k}^{*} \mathrm{t}\right)\right)($ Gompertz 1825) \\
IPT & $\ln (\mathrm{b}) / \mathrm{k}$ \\
$\mathrm{IPW}$ & $\mathrm{A} / \mathrm{e}$ \\
Richards & $\mathrm{Wt}=\mathrm{A} *\left(1+\mathrm{b}^{*} \exp \left(-\mathrm{k}^{*} \mathrm{t}\right)\right)-1 / \mathrm{d}($ Richards 1959$)$ \\
IPT & $-1 / \mathrm{k}^{*} \ln |\mathrm{d} / \mathrm{b}|$ \\
IPW & $\mathrm{A} /(\mathrm{d}+1) 1 / \mathrm{d}$ \\
Logistic & $\mathrm{Wt}=\mathrm{A} *\left(1+\mathrm{b}^{*} \exp \left(-\mathrm{k}^{*} \mathrm{t}\right)\right)-1$ (Verhulst 1838) \\
IPT & $\ln (\mathrm{b}) / \mathrm{k}$ \\
IPW & $\mathrm{A} / 2$ \\
\hline Wt is body weight $(\mathrm{BW}, \mathrm{kg})$ of the animal at age t, day; $(\mathrm{A})$ is predicted final weight or asymptotic weight, $\mathrm{kg} ;(\mathrm{b})$ Constant \\
of integration;(k) is growth parameter indicates the maturingrate;(d) is shape parameter in Richards model; eis the base of the \\
natural logarithm $(\sim 2.71828 \ldots) ;$ IPT: time at point of inflection; IPW: weight at point of inflection.
\end{tabular}

\section{Goodness-of-fit criteria:}

The goodness-of-fit criteria to compare the studied functions that explain the growth are as follows:

- Determination Coefficient, R2 = 1- (SSE/SST)

- Mean Square Error, MSE $=\mathrm{SSE} /(\mathrm{n}-\mathrm{k})$

- Akaike's Information Criteria, (AIC; Akaike1973)

$=\mathrm{n} \cdot \ln (\mathrm{SSE} / \mathrm{n})+2 \mathrm{k}$

- Schwarz Bayesian Information Criterion, (BIC;Schwarz, 1978)

$=\mathrm{n} \cdot \ln (\mathrm{SSE} / \mathrm{n})+\mathrm{k} \cdot \ln (\mathrm{n})$

Where: SST the total sum of squares, SSE is the sum of square errors, $\mathrm{n}$ is the number of observations, and $\mathrm{k}$ the number of parameters. The best model should have the lowest values for AIC, BIC, MSE, and highest R2.

\section{RESULTS AND DISCUSSION}

Means \pm standard errors for observed live weight of Holstein-Friesian bulls are presented in Table 2. According to the data obtained, the averages of weight at birth and final live weight at 17 months of age were found to be $34.87 \pm 0.84 \mathrm{~kg}$ and $580.00 \pm 7.98$ $\mathrm{kg}$, respectively. As the animals get older, the standard error values for body weights become higher.Coefficient of variation (CV \%) had the highest values at ages of 120,150 and 180 days compared with other different ages.

In this study, the averages of live body weights are in agreement with the previous study of Tutkun (2019).

Table 2. Observed means and standard errors of Holstein bulls weights by age

\begin{tabular}{lccc}
\hline Age (days) & Mean $(\mathrm{kg})$ & SE & CV\% \\
\hline Birth & 34.87 & 1.50 & 3.86 \\
30 & 51.43 & 3.05 & 8.08 \\
60 & 77.50 & 3.21 & 9.25 \\
90 & 105.52 & 3.29 & 11.81 \\
120 & 141.55 & 3.39 & 12.23 \\
150 & 172.79 & 3.98 & 12.47 \\
180 & 201.72 & 4.10 & 12.50 \\
210 & 232.43 & 4.21 & 11.80 \\
240 & 269.22 & 4.49 & 11.18 \\
270 & 303.13 & 4.86 & 9.75 \\
300 & 338.81 & 5.01 & 9.15 \\
330 & 384.76 & 5.33 & 9.28 \\
360 & 411.38 & 5.68 & 9.39 \\
390 & 459.50 & 5.95 & 10.58 \\
420 & 598.50 & 6.21 & 11.21 \\
450 & 530.50 & 6.57 & 11.54 \\
480 & 555.00 & 7.12 & 10.78 \\
510 & 580.00 & 7.98 & 11.05 \\
\hline
\end{tabular}


In this study, the parameters of studied models, A, $\mathrm{b}$, and $\mathrm{K}$ ranged from $626.15 \mathrm{~kg}$ to $879.82 \mathrm{~kg}, 2.708$ to 11.08 , and 0.0035 to 0.008 , respectively (Table 3 ). According to the studied growth functions, Gompertz reached the highest numerical estimated value for the asymptotic weight (A) and the Logistic function had the lowest value. Although the Gompertz model had the highest asymptotic weight value, the Richards model was the best to fit the data depending on the goodness of fit criteria and asimilar trend was found by Selvaggi et al., (2017). The estimated maturity rate parameter $(\mathrm{K})$ by the Gompertz model was similar to that obtained by the Richards model; both values were lower than those attained through the Logistic model (0.008). The estimates of asymptotic weight $(\mathrm{A})$ and maturity rate $(\mathrm{K})$ in this work are in line with the previously reviewed studies with Holstein bulls.Velásquezet al. (2013) estimated the values of $\mathrm{A}$ and $\mathrm{K}(795 \mathrm{~kg}$ and 0.0047 , respectively) for the Gompertz model. Furthermore, the values of asymptotic weight (A), the maturity rate $(\mathrm{K})$, and the integration constant (b) as shown in (Table 3 ) did not considerably differ, compared with other studies with Holstein-Friesian bulls. Tutkun (2019) estimated A, $\mathrm{K}$, and $\mathrm{b}$ values of $986.44,0.004$ and 3.354 for the Gompertz model and 1110.24, 0.003, 0.299 for the Richards model and 672.94, 0.008 and 13.76 for the Logistic model. There is an antagonistic genetic correlation between parameters A and K (Silva et al.,
2002). Several factors can affect estimates of growth parameters such as the mother's age (Silva et al., 2002), season (Nuru et al., 1981), year of birth (Quaas, 1983) in addition to mature weight and maturity rate (McLaren et al., 1982). In this study, Parameters $\mathrm{A}$ and $\mathrm{k}$ showed a distinct converse relationship, where animals with heavier asymptotic weight (A) values presented the slowest maturity rate (k) values. On the other hand, animals that grew with fast maturity rates were lighter at maturity. Hence, there was an inversed relationship between mature weight and maturity rate (Bullock et al., 1993 and Perotto et al., 1994).

The IPT and IPW estimates of the HolsteinFriesian bulls are presented in Table 3. In this study, the parameters of studied models, IPT, and IPW estimates ranged from 300.64 to 314.59 and 323.92 to 336.14 , respectively. The Richards model has the highest estimates of IPW and IPT compared to the other models. Tutkun (2019) calculated IPT and IPW estimates of 306.75 days and $362.89 \mathrm{~kg}$ for the Gompertz model,400.14days, $545.01 \mathrm{~kg}$ for the Richards model and 327.72 days and $336.47 \mathrm{~kg}$ for the Logistic model for Holstein-Friesian bulls. Regarding studied growth models, the inflection point estimates in this study were lower than those estimated by Tutkun (2019). The estimates of the growth function parameters are presented in Table 3.

Table 3. Estimated parameters and their standard error $( \pm \mathrm{SE})$ of growth models and inflection point traits

\begin{tabular}{lccc}
\hline Parameter & Gompertz & Richards & Logistic \\
\hline A & $879.82 \pm 2.78$ & $660.18 \pm 6.85$ & $626.15 \pm 1.03$ \\
B & $3.33 \pm 0.01$ & $2.708 \pm 0.001$ & $11.08 \pm 0.08$ \\
K & $0.004 \pm 0.0004$ & $0.0035 \pm 0.0001$ & $0.008 \pm 0.0005$ \\
D & - & $1.092 \pm 0.048$ & - \\
IPT & 300.74 & 314.59 & 300.64 \\
IPW & 323.92 & 336.14 & 328.07 \\
\hline
\end{tabular}

SE: stander error,A: asymptote weight, b: scale parameter, k: relative growth rate, d: shape parameter, IPT: point of inflection time (days), and IPW: point of inflection weight $(\mathrm{kg})$.

The goodness of fit for the different growth functions are presented in Table 4. Based on the goodness of fit criteria, the AIC, BIC, R2, and MSE criteria can determine how well the models fit a database. The estimates for the three studied growth functions were equivalent and have considerably high and similar R2 values (close to 1) which ranged from 0.9978 to 0.9983 indicating that all models had a good performance (fitting) in describing live weight changes related to age in Holstein-Friesian bulls. High R2 estimates have been reported by many authors (Velásquez et al., 2013, Koşkan and Özkaya, 2014 and Tutkun, 2019). According to model goodness of fit criteria, the Richards model had the best adjustment, having the lowest values for AIC, BIC, MSE, and highest R214489.18, 14510.6, 317.37 , and 0.9983 , respectively, followed by the Gompertz, and logistic functions (Table 4). Several studies reported that Richards model was the best for describing growth pattern in cattle (Tjørve and Tjørve, 2010; Velásquez et al., 2013; Goldberg and
Ravagnolo, 2015; Gano et al., 2016 and Tutkun, 2019). The logistic function was found to be the least accurate based on AIC and BIC (Forni et al., 2009, Gano et al., 2016 and Selvaggi et al., 2017). The estimates of AIC and BIC showed wide range reported by many authors ( 42.05 to 201857 and 41.43 to 201889, respectively) for the Gompertz model (Velásquezet al.,2013, Goldberg and Ravagnolo, 2015 and Gano et al., 2016) ranging from 183379 to 189150 and 183560 to 189189 , respectively for Richard model and ranging from 184623 to 206277 and 184749 to 206309, respectively for Logistic model (Goldberg and Ravagnolo, 2015 and Gano et al., 2016).

The tested models showed a very similar trend regarding their ability to fit throughout the studyperiods (Figure 1). The difference between actual and predicted values was very similar among the evaluated models (Figure 1), indicating that the observed weight of theanimal was identical to predicted by the models through the time 
Table 4. The goodness of fit criteria for fitted growth functions

\begin{tabular}{lccc}
\hline Criterion & \multicolumn{3}{c}{ Growth functions } \\
\cline { 2 - 4 } & Gompertz & Richards & Logistic \\
\hline $\mathrm{R}^{2}$ & 0.9981 & 0.9983 & 0.9978 \\
$\mathrm{MSE}$ & 355.05 & 317.37 & 336.12 \\
$\mathrm{AIC}$ & 14548.78 & 14489.18 & 14553.63 \\
$\mathrm{BIC}$ & 14570.21 & 14510.60 & 14580.41 \\
\hline
\end{tabular}

R2:coefficient of determination, MSE: mean square error, AIC: Akaike information criterion, and BIC: Schwarz Bayesian information criterion.

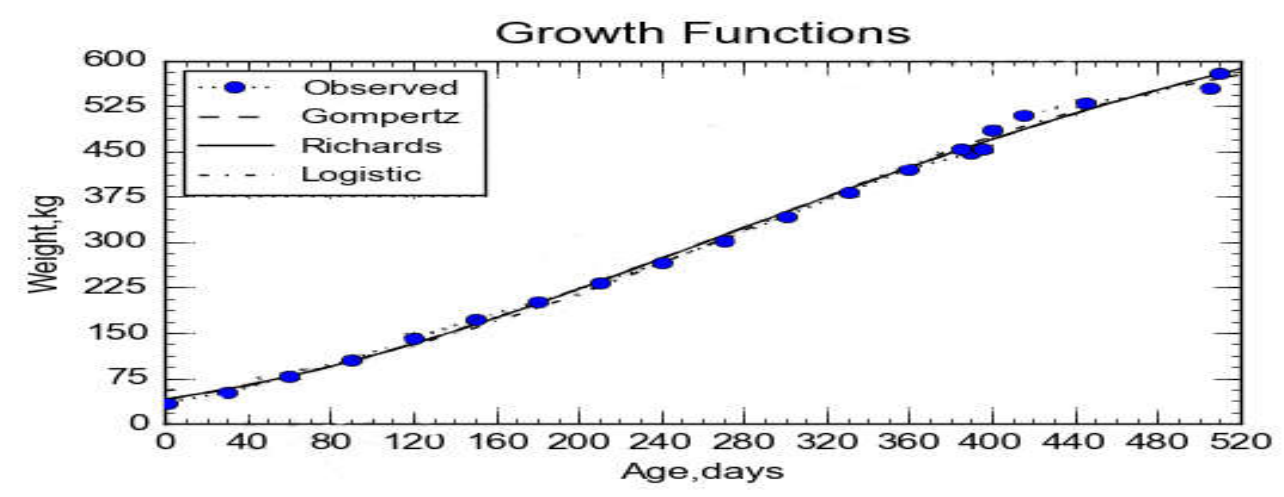

Figure 1. Growth curves of Holstein-Friesian bulls according to logistic, Gompertz, andRichards models in comparison to the observed data.

\section{CONCLUSION}

According to model goodness of fit criteria, the Richards model was the best to fit the data of Holstein-Friesian bulls by having the lowest values for (AIC), ( BIC), (MSE), and highest value for (R 2) followed by the Gompertz, and logistic functions.

\section{REFERENCES}

Bullock, K.D., J.K. Bertrand, and L.L. Benyshek, 1993. Genetic andenvironmental parameters for mature weight and other growth measuresin Polled Hereford cattleJournal of Animal Science, 71: 1737-1741.

Calo, L. L., R. E., McDowell, L.D, Van VlecK and P.D, MilleR, 1973. Parameters of growth of Holstein-Friesian bulls. Journal of Animal Science, 37(2): 417-422.

Duarte, F.A.M, 1975. Estudo da curva de crescimento de animais da raça "Nelore" (Bos taurus indicus), através de cinco modelos estocásticos. Associate Professor Thesis, , Universidade de São Paulo, Ribeirão Preto, Spain.

Forni, S., M. Piles, A. Varona , H. N. D. Oliveira, R. B. Lôbo, and L. G. D. Albuquerque, 2009.Comparison of different nonlinear functions to describe Nelore cattle growth. Journal of Animal Science, 87(2), 496-506.

Freitas, A.R, 2005. Curvas de crescimento na produção animal. Revista Brasileira de Zootecnia, (34): 786-795.
Gano, G., M. Blanco, I. Casasús, X. Cortés-Lacruz and D. Villalba, 2016. Comparison of B-splines and non-linear functions to describe growth patterns and predict mature weight of female beef cattle. Animal Production Science, 56, 17871796.

Goldberg,V. and O. Ravagnolo, 2015.Description of the growth curve for Angus pasture-fed cows under extensive systems.Journal of Animal Science. 93:4285-4290.

Koşkan, Ö., and S. Özkaya, 2014. Determination of growth curves of female Holstein calves using five non-linear models.Pakistan Journal of Agricultural Sciences51(1): 225-228.

Lawrence, T.L.J. and V.R. Fowler, 2002. Growth of farm animals 2nd Edn. CAB International, Wallingford, UK.

McLaren, J.B., R.E. Morrow and W.T. Butts, 1982. Impact of numbers and frequency of weighings on bovine weight-age curve parameters. Journal of animal science. 54: 51-57.

Nuru, S., V. Buvanendran and S.M. Abed, 1981. Growth rates of Wadaradand Shorthorn-Wadara crossbred cattle in the northeastern of Nigeria. Journal of Animal Production Research (Nigeria). 1: 123-124.

Perotto, D., R.I. Cue, A.J. Lee, A.J. McAllister, T.R. Batra, C.Y. Lin,G.L. Roy andJ.M. Wauthy, 1994. Additive and non-additive genetic effects of growth-curve parameters of Holstein, Ayrshire and crossbred females. Canadian Journal of Animal Science 74: 401-409. 
Quaas, R.L, 1983. Genetic variation in growth curves of Hereford females. Ph.D. thesis, Colorado State University, Colorado.

SAS, Institute Inc, 2011. SAS/STAT ${ }^{\circledR} 9.3$ Userand\#39; s Guide. Cary, NC: SAS Institute Inc.

Selvaggi, M., V. Laudadio, A. Gabriella, D. Alessandro and C. Dario, 2017. Comparison on accuracy of different nonlinear models in predicting growth of Podolica bulls. Animal Science Journal, 88 (8):1128-1133.

Silva, F.F, L.H. Aquino and A.I. Oliveira, 2002. Estimativas de parâmetros genéticos de curva de crescimento de gado nelore (Bos indicus). Ciênc Agrotec, 34:1562-1567.

Souza, L.D.A., D.N. Caires, P.L.S. Carneiro, C.H.M. Malhado and R. Martins Filho, 2010. Curvas de crescimento em bovinos da raça Indubrasil criados no Estado do Sergipe. Revista Ciência Agronômica, 41(4), 671-676.

Tjørve, E. and K.M.C. Tjørve, 2010. A unified approach to the Richards-model family for use in growth analyses: why we need only two model forms. Journal of Theoretical Biology, 267: 417425.

Tutkun, M, 2019.Growth Curve Prediction of Holstein-Fresian Bulls Using Different NonLinear Model Functions. Applied Ecology and Environmental Research, 17(2), 4409-4416.

Velásquez R, R.R. Noguera, S.L. Posada, A. Hoyos and J.M. Cerón, 2013. Estimation of growth in intact grazing Holstein steers. Revista Colombiana de Ciencias Pecuarias, 26.3: 169-176
Wada, Y., T. Matsukawa and Y. Sasaki, 1983. Describing weight-age relationships in Japanese Black females with non-linear growth models. In World Conference on Animal Production, 5. Proceedings of the Japanese Society of Zootechnical Science, Tokyo, pp: 33-34.

Yin, T. and S. König, 2020. Genomic predictions of growth curves in Holstein dairy cattle based on parameter estimates from nonlinear models combined with different kernel functions. Journal of Dairy Science, 103.

Richards, JF, 1959A flexible growth function for empirical use. Journal of Experimental Botany 10, 290-300.

Gompertz, B, 1825. On the nature of the function expressiveof the law of human mortality, and on a new modeof determining the value of life contingencies. PhilosophicalTransactions of the Royal Society of London 115,513-585.

Verhulst, PF, 1838. Notice sur la loi que la population pursuitdans son accroissement. Correspondance Mathématique et Physique10, 113-121. (In French)

Akaike H, 1973. Information theory and an extension of the maximum likelihood principle.In: B.N. Petrov and F.Csaki, editors. 2ndInternational Symposium on Information Theory:267-281.

Schwarz G, 1978. Estimating the dimension of a model. Annals ofstatistics 6,461-464.

\section{مقارنة ثلاثة نماذج غير خطية لوصف منحنى النمو لذكور الفريزيان المرباة تحت الظروف المصرية} رشا عبدالحمبذ محمود صميده

$$
\text { قسم الإنتاج الحيوانسي، كلية الزراعة، جامعة الفيوم. }
$$

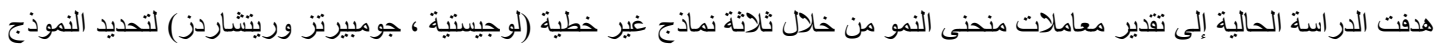

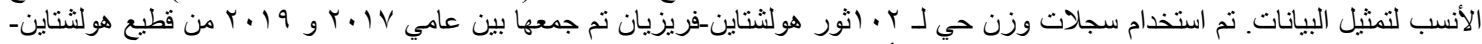

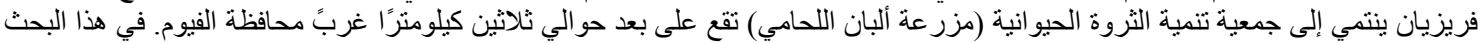

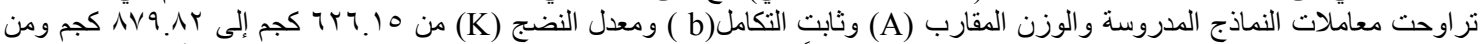

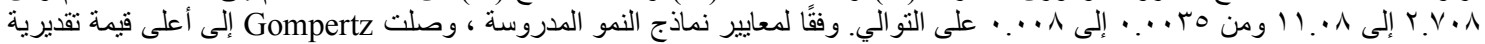

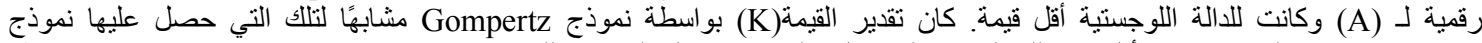

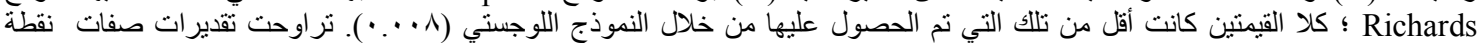

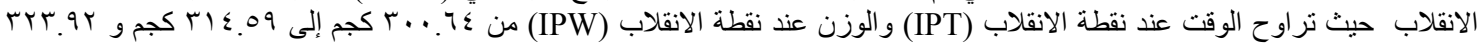

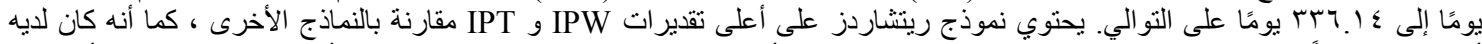

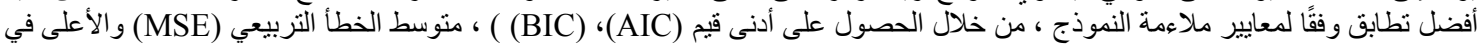
معامل التحديد \}2) 